\title{
INMIGRANTES PERUANAS EN ESPAÑA Conquistando el espacio laboral extradoméstico
}

\author{
ANGELES ESCRIVÁ CHORDÁ \\ IESA-CSIC, Córdoba
}

\section{PALABRAS CLAVE ADICIONALES}

Movilidad socio-laboral, Servicio doméstico,

Estratificación étnica, Trato legal preferencial,

Conciliación trabajo doméstico y remunerado.

\section{ADDITIONAL KEYWORDS}

Social and Occupational Mobility, Domestic Service, Ethnic Stratification, Legal Preferential Neatment, Domestic and Paid Work Conciliation.

RESUMEN. La sustitución de mujeres inmigrantes de unas nacionalidades por otras es un fenómeno bastante frecuente en el ámbito de la inmigración. El caso de las peruanas en España lo confirma con claridad. En este artículo se analiza dicho fenómeno social explicando por qué comparativamente las peruanas muestran algo más de movilidad ocupacional que las mujeres de otras nacionalidades que incluso llevan más tiempo en España. El artículo recalca que los nuevos puestos conquistados siguen mostrando mayormente la característica de ser poco cualificados, poco remunerados y considerados, reincidiendo en la asignación de tareas de servicio calificadas de femeninas y poco reconocidas en las mujeres. La reflexión final apunta a que sigue abierto el debate sobre la consideración social del trabajo doméstico, el reparto de estas tareas entre los géneros, y la necesaria conciliación del hogar con el empleo remunerado.

ABSTRACT. A substitution of women from different nationalities and from different lenghts of stay, in the worst paid an most limiting jobs, is possible because there are some determining factors here appointed. All together explain why Peruvian women as a whole show comparatively slightly more occupational mobility that women from other nationalities who may be even longer in Spain. However, the article remarks that the new conquered jobs are still low qualified, low paid and considered, falling back into the assigment of femenine and low recognised service tasks on women. The final consideration suggests that the debate about the social valorization of domestic work, the share of these duties between men and women and the necessary conciliation of the housework with the paid work, is still open.

E-mail: aescriva@iesaa.csic.es

Revista Internacional de Sociología (RIS)

Tercera Época, No 36, Septiembre-Diciembre, 2003, pp. 59-83. 
RIS

REVISTA INTERNACIONAL DE SOCIOLOGIA

№ 36, Septiembre-Diciembre, 2003

ANGELES ESCRIVÁ CHORDÁ

\section{INTRODUCCIÓN}

En un artículo aparecido en la revista Papers (Escrivá, 2000), número monográfico sobre la Inmigración Femenina en el Sur de Europa, se argumentaba sobre la dificultad para la gran mayoría de las peruanas de abandonar sus actividades laborales en el sector del servicio doméstico en Barcelona en pos de empleos más cualificados o en otras áreas de actividad.

Se destacaba allí que estas mujeres inmigradas habían expresado - durante el trabajo de campo que originó el artículo, es decir, entre los años 1995 y $1999^{1}$ - su frustración inicial y su consecuente malestar con el empleo como domésticas en España. Ellas deseaban y se sentían capacitadas por su cualificación y experiencia profesional para realizar otros trabajos que gozaban de una mayor consideración social y que, por tanto, estaban mejor recompensados.

No obstante el tiempo transcurrido desde el arribo a España, todavía en la segunda mitad de la década de los años noventa la gran mayoría de peruanas continuaba ejerciendo labores remuneradas dentro de los hogares españoles - aunque ahora ya las más veteranas en gran medida en régimen de externas-, y sólo unas pocas empezaban a desempeñar trabajos fuera del ámbito doméstico, como los de limpieza de edificios y oficinas, restauración y despacho y ventas.

En el análisis de esta situación tomaba en consideración: las constricciones impuestas por la legislación sobre extranjería, el mercado de trabajo y las redes sociales que estaban posibilitando (podemos decir incluso, induciendo) la emigración de otros paisanos y su rápida colocación en un sector económico determinado. Como determinantes personales en la inserción laboral consideraba: la situación en el ciclode vidade lasmujeres, sus necesidades económicas, su formación y experiencia laboral anterior, y los elementos constituyentes de su identidad de clase y género.

\footnotetext{
${ }^{1}$ El trabajo de campo al que hacemos mención se realizó en varias etapas. Una primera estuvo compuesta por una treintena de entrevistas biográficas en Barcelona a mujeres peruanas llegadas entre fines de los años ochenta y mediados de los noventa, por tanto, en diferentes situaciones vitales en términos de edad, estado civil e hijos, estatus legal, experiencia laboral y educativa en el lugar de origen, etc. Las entrevistas grabadas se realizaron después de hacer un estudio exhaustivo de los perfiles de las inmigrantes peruanas según se desprendía de los archivos consulares y de las fichas de inscripción de varias parroquias barcelonesas donde las mujeres acudian a solicitar intermediación en la colocación como domésticas. Este trabajo estadístico fue completado con numerosas anotaciones registradas mediante la observación participante en asociaciones, fiestas y lugares de encuentro de peruanas. Finalizada la primera etapa del estudio, se llevó a cabo otra ronda de entrevistas y recopilación estadística y documental en Perú a peruanas retornadas, y a familiares de las emigradas, conforme a las direcciones que ellas mismas facilitaron. Por último, tres años más tarde, se recogieron de nuevo testimonios grabados de media docena más de peruanas e información indirecta de otras tantas que habian sido entrevistadas en la primera fase, pudiendo asi ver los cambios en sus trayectorias socio-laborales.
} 
Pocos años después de haber sido publicado el artículo referido, sin embargo, se puede observar en las grandes ciudades españolas el desplazamiento de más peruanas hacia la realización de trabajos extra-domésticos. Mientras esto sucede, sus antiguos puestos como cuidadoras y mantenedoras de los hogares son ocupados por nuevas inmigrantes de su mismo país, pero, sobre todo, por mujeres de otras nacionalidades como la ecuatoriana y la colombiana. Ello podría estar dando pie a una movilidad ocupacional intrageneracional en sentido ascendente entre aquellas mujeres que cuentan con las condiciones necesarias para una situación supuestamente más favorable. A la par se podrían estar generando situaciones desiguales entre mujeres de la misma nacionalidad y entre inmigrantes de diferentes nacionalidades. Serían factores explicativos de esta desigual integración laboral, entre otros, el tiempo de estancia en el país y otros aspectos diferenciales de clase, género y etnicidad.

Es objetivo de este ensayo la discusión sobre la integración laboral de las mujeres de origen inmigrante extracomunitario. También lo es analizar las características de los nuevos puestos que ocupan las peruanas en España, los determinantes de esta movilidad laboral y los límites y efectos que pueden observarse, tanto desde la perspectiva de las propias mujeres como desde la estructura de relaciones étnicas y de género en la sociedad española. Para ello, en primer lugar procedemos a realizar una crítica de la perspectiva integracionista en el estudio sobre la inserción y la movilidad laboral de las personas de origen extranjero inmigrante por no reconocer la especificidad de las mujeres.

\section{INTEGRACIÓN LABORAL DE LAS MUJERES INMIGRADAS}

El concepto de integración relacionado con la inmigración ha sufrido múltiples y dispares interpretaciones desde su aparición en los debates académicos, a partir de los años 70 en Europa (Bauböck, 1994). Entendemos aquí la integración laboral de las personas en España, en tanto que sociedad compleja avanzada, como un proceso positivo de inserción en el tejido económico que permita la posterior mejora o movilidad ocupacional ascendente de los individuos. La inserción y la movilidad son medidas ambas en términos de ingresos, condiciones laborales, y prestigio de la ocupación. El retroceso o estancamiento ocupacional en condiciones consideradas adversas puede ser considerado, por el contrario, como un signo de "desintegración".

De este modo, integración y movilidad ocupacional quedan íntimamente ligadas. Generalmente, los estudios sobre inmigración se han interesado por la movilidad intergeneracional de los hijos y nietos de emigrantes, bajo el supuesto de que, los que primero llegaron, partían de su lugar de origen con niveles bajos o medios de estudios y/o capacitación y que, por tanto, la movilidad ascendente sólo era de esperar en sucesivas generaciones mejor preparadas. Hoy por hoy, 
R IS

REVISTA INTERNACIONAL DE SOCIOLOCIA

No 36, Septiembre-Diciembre, 2003

ANGELES ESCRIVÁ CHORDÁ

sin embargo, muchos otros estudios empiezan a centrarse en la movilidad intrageneracional de las personas que son sujetos activos en los procesos migratorios internacionales (Oso, 2002; Liem, 2000). Este interés surge por la constatación de que: a) quienes salen de los países de origen en muchos casos son ya personas con elevados niveles de estudios y/o capacitación; y que, b) no todos los inmigrantes tienen hijos o piensan tenerlos y, por tanto, no cabe esperar que la estrategia sea sacrificar la carrera personal por el bien de ellos - lo cual ha podido ser constatado en nuestro estudio con un número de peruanas sin hijos que igualmente han tenido que insertarse inicialmente en el mercado laboral como domésticas.

A pesar de su pretendida universalidad, la integración laboral, entendida del modo en que lo hemos hecho, no puede contener a todos los sujetos que habitan en las sociedades avanzadas contemporáneas. En éstas siguen existiendo numerosos trabajos en pésimas condiciones y poco deseados - pese a la tecnologización-, además de numerosas constricciones a la movilidad, con lo que no todas las personas pueden insertarse y mejorar su situación a lo largo del tiempo según los estándares socialmente aceptados.

En los estudios migratorios comparados se muestra que, frecuentemente, los recién llegados del Tercer Mundo deben conformarse con los puestos menos deseados: los más duros, los peor pagados, los más inestables, los menos prestigiosos del mercado laboral (Castles, 1998). Ello queda favorecido por la situación de indocumentación o dependencia legal o contractual en la que muchas personas se encuentran en la primera etapa. También las condiciones y características de la red social en la que se insertan -incluso antes de la emigración - condicionan sus posibilidades de colocación y posterior promoción. Por no decir del clima social de aceptación vigente en la sociedad receptora.

Los enfoques que equiparan integración con asimilación esperan que, a medida que avance el tiempo, los inmigrantes consigan mejorar su posición en la estructura social hasta alcanzar en la segunda y posteriores generaciones niveles idénticos de distribución de individuos en el tejido social y productivo que la población de origen autóctono. Los medios que la sociedad receptora pone para ello son, principalmente, la otorgación de los derechos de ciudadanía y la puesta a disposición de los recursos sociales necesarios para afrontar el mercado laboral en mejores condiciones, básicamente con la educación. Por parte de los inmigrantes, en el proceso se les exige la adopción de nuevos valores culturales y de las prácticas socio-económicas y políticas que de ellas se deriven.

La realidad es que, si bien éste pudiera ser el caso en algunos de los procesos migratorios estudiados - principalmente desde la óptica de la sociología funcionalista estadounidense con su ideario sobre el melting pot (Sowell, 1997)-, pervive con demasiada frecuencia el estancamiento, incluso el retroceso, en las trayectorias laborales de los inmigrantes y de sus descendientes. Y las diferencias entre grupos pueden ser explicadas en términos de producción y reproducción de desigualdades de clase, etnicidad, y género, principalmente. 
Ejemplificando lo anterior, en la Europa Occidental, partiendo de padres situados en puestos estables y suficientemente remunerados en la escala de obreros y técnicos que fueron reclutados en las décadas de los años 50-70, muchos hijos con estudios medios y superiores se han encontrado con muchísimas más dificultades para insertarse cualificadamente en el mercado laboral que sus progenitores. Esto, que no es ninguna novedad por cuanto afecta a toda la población, lo hace en mucha mayor medida entre los jóvenes de origen inmigrante -más entre los de unos orígenes que los de otros y, de entre ellos, especialmente afecta a las mujeres (Werner, 1993).

La tendencia hacia el desempleo y la inestabilidad laboral que afectan actualmente en mayor o menor medida a todas las cohortes y sexos se tiende a explicar por la exigencia de flexibilidad del factor mano de obra en las economías, a su vez que, entre otras razones, por la escasez de empleos ante una oferta de mano de obra cada vez más cualificada y exigente. En el caso de los grupos más vulnerables - jóvenes, mujeres, y/o pertenecientes a minorías étnicas (inmigradas) - coexisten, además, alarmantemente el subempleo y la temporalidad. Estas condiciones laborales dan pocas esperanzas a la posibilidad de realizar trayectorias laborales marcadas por la integración.

Las razones para el desigual impacto por orígenes y sexos de la reestructuración laboral cabe hallarlas en las estructuras de oportunidades y constricciones que la sociedad establece bajo relaciones de jerarquía y poder. Estas estructuras acostumbran a producir un discurso de manera que parezcan ser los rasgos psicológicos y culturales de las personas y grupos quienes determinen que, si los jóvenes, las mujeres - en cualquiera de las etapas de su vida - y las minorías étnicas no encuentran o no disponen de un empleo atractivo, es porque sus propios rasgos culturales, psicológicos -incluso se dirá que hasta físicos- se lo impiden.

\section{MIGRACIÓN, GÉNERO Y TRABAJO DOMÉSTICO}

Hasta ahora hemos producido un discurso supuestamente neutro en términos de género sobre la integración laboral. Sin embargo, hemos reincidido a propósito en el típico error de no subrayar las diferentes relaciones que hombres y mujeres mantienen con el trabajo. El análisis con perspectiva de género revela que no hay aproximación neutra posible cuando tratamos del trabajo (Borderías et al., 1994). Hombres y mujeres suelen presentar diferentes patrones de "integración laboral", determinados por factores como: la biografia personal, las preferencias del mercado, los niveles educativos y profesionales adquiridos, las estrategias de inserción utilizadas y, claro está también, por la legislación vigente y las normas socialmente aceptadas. Estas últimas disponen que las mujeres han de realizar ambos trabajos, el doméstico y el extradoméstico.

Por un lado, existe una desatención en el estudio de la integración laboral en 
RIS

REVISTA INTERNACIONAL DE SOCIOLOGIA

№36, Septiembre-Diciembre, 2003

ANGELES ESCRIVÁ CHORDÁ

lo que se refiere a su interdependencia con otros órdenes de la vida que no estrictamente el trabajo remunerado. A menudo se olvida que no todas las personas desean o están en disposición de realizar un trabajo remunerado (o no a tiempo completo) en todo el periodo de su vida adulta. Ello es especialmente válido en el caso de las mujeres (Poal, 1993). Marcadas por el ciclo de vida, el matrimonio y la maternidad principalmente, pero también por su rol como cuidadoras de otras personas y mantenedoras del hogar, muchas mujeres dejan total o temporalmente, o no ejercen desde la juventud, la actividad laboral remunerada. Y con ello se encuentran con mayores dificultades para (re)emprenderla en el momento que lo desean, peor aún en los niveles que ellas esperan, por sus cualificaciones y experiencias anteriores.

Por otro lado - y aunque parezca contradecirse con lo anterior- se asume que el trabajo doméstico es cosa de mujeres. Su bajo nivel de consideración social, reforzado por su invisibilidad en las economías nacionales, convierte a ese otro tipo de trabajo en un no-trabajo, con lo cual deja de contabilizarse como experiencia laboral en la medición de la movilidad ocupacional, o bien se contabiliza en lo más bajo si se desempeña a cambio de un sueldo, es decir, cuando existe contratación (Carrasco, 1991). Como resultado, cada vez menos mujeres desean dedicarse en exclusiva a las tareas domésticas sin recibir ningún tipo de recompensa salarial y reconocimiento social. Las mujeres que no disponen de suficientes recursos deben compaginar la doble dedicación al trabajo fuera y dentro del hogar en detrimento de ambas esferas. $\mathrm{Y}$ aquéllas con mayores posibilidades económicas y sociales deciden derivar estas tareas hacia otras personas a las cuales hoy todavía se les contrata en régimen de semi-servidumbre en España.

De este modo, y bajo las presentes circunstancias, la integración laboral de las mujeres autóctonas seguirá requiriendo su sustitución por mujeres pobres o empobrecidas del Tercer Mundo en la realización de las obligaciones domésticas. Esta sustitución tiene el efecto de perpetuar la imagen subordinada de las mujeres, con nuevos tintes étnicos, a la vez que muchas de ellas sufren ahora movimientos descendentes en sus carreras profesionales/educativas/sociales previas ejercidas en el lugar de origen.

Las ventajas que extrae la sociedad española de esta contratación femenina inmigrante son múltiples: por un lado, consigue cubrir un nicho laboral que la población autóctona ha ido abandonando y se prevé en aumento; por otro lado, los contingentes contienen la posibilidad para los y las inmigrantes de optar por otro tipo de puestos que pudieran suponer una competencia para la población autóctona; además, el régimen especial del servicio doméstico incide en la desigualdad de los trabajadores en cuanto a condiciones de trabajo y beneficios sociales, puesto que no cubre el seguro por desempleo, y las jubilaciones y otras coberturas por enfermedad, maternidad, entre otras son notoriamente inferiores a las de otros sectores laborales (MTAS, 1997).

Asimismo, las extranjeras recién llegadas pueden considerar apropiadas las 
características de los nuevos puestos que desempeñan como trabajadoras del hogar porque: a) sirven de vía rápida para la regularización, b) no exigen destrezas especiales que no puedan demostrarse, y c) permiten un ahorro sustancioso del sueldo que se destina al pago de deudas y a las remesas. De hecho no pocas de estas personas manifiesta su idoneidad con los planes migratorios temporales (Escrivá, 1999). El malestar surge cuando las relaciones laborales y personales en el hogar empleador son malas; el trabajo es frustrante para la persona que lo realiza porque se siente más cualificada o preparada para realizar otro tipo de labores $\mathrm{o}$, al menos, en otro ambiente; y sobre todo, cuando el proyecto migratorio va convirtiéndose en algo a largo plazo que incluye la reagrupación familiar y la mirada al nuevo país como lugar de asentamiento.

Evidentemente no podemos generalizar hablando de dos situaciones totalmente polarizadas: las autóctonas completamente integradas laboralmente frente a las (de origen) extranjeras totalmente excluidas. Encontramos en el panorama laboral español un surtido repertorio de situaciones. Las dificultades para insertarse, mantenerse y estabilizarse avanzando en el mercado laboral existen para la mayoría. En cambio, sí podemos hablar de unas tendencias que se van perfilando. La sociedad receptora va creando sus mecanismos discriminantes para conseguir que los puestos menos deseados recaigan en las personas de ciertos orígenes étnicos ${ }^{2}$. A la cuestión del trabajo doméstico, por el contrario, no se le buscan soluciones alternativas: si no son unas, tendrán que ser otras mujeres quienes lo ejerzan, puesto que ni el Estado, ni el sistema económico, ni la otra parte, la masculina, tienen la mínima intención de asumir seria e integralmente el tema.

Si hemos argumentado sobre la dispar condición entre la población de origen extracomunitario y la población autóctona, y entre las mujeres de ambos extractos, también podemos cuestionar la bastante arraigada creencia de que las mujeres de origen inmigrante son más susceptibles de integrarse laboralmente en España que los hombres de su mismo origen. Las cifras del Anuario Estadístico de Extranjería (DGEI, 2002) demuestran que no es nada desdeñable el número de hombres inmigrantes que trabaja al menos temporal o esporádicamente en el servicio doméstico. Al menos oficialmente, a primeros del año 2002 había 2.349 varones de alta en el régimen de empleados del hogar de la seguridad social.

\footnotetext{
${ }^{2}$ Diversos mecanismos discriminatorios actúan en pos del mantenimiento de un sistema social desigual justificado en la protección de la "nacionalidad" y los beneficios que ésta conlleva para quienes son sus propietarios. Por ejemplo, la reserva de los puestos de trabajo doméstico - principalmente en régimen interno- a los (algunos) hombres y, sobre todo, a las mujeres que vienen de paises menos desarrollados económicamente, está legalmente tipificada en los contingente anuales que oferta el gobierno español.
} 
RIS

REVISTA INTERNACIONAL DE SOCIOLOCIA

Aparte de esta posibilidad, ellos disponen de una mayor variedad de puestos y ocupaciones donde probar: construcción, agricultura, hostelería, comercio, etc. Las cualificaciones masculinas que puedan traer consigo - a excepción quizás de los oficios de sanitarias de las mujeres - tienen una mayor demanda y prestigio en el mercado laboral y les pueden permitir el empleo por cuenta propia (en profesiones tales como la mecánica, la fontanería, la electricidad). Además, sus menores compromisos familiares (patentes en la cantidad de las remesas que envían al país de origen) les puede ayudar a invertir en sus futuros profesionales, mirando más en su beneficio propio que en el de los demás (Naciones Unidas, 1997).

El detenerse en estos aspectos se debe a que se tiende a pensar que las mujeres procedentes, por ejemplo, de Filipinas o de la República Dominicana, que viven entre nosotros han alcanzado un elevado grado de integración laboral puesto que raramente las encontramos haciendo cola en los servicios sociales o en el INEM -en contraposición, a lo que normalmente se percibe de los hombres marroquíes. En términos de inserción laboral probablemente sí, por cuanto la nutrida demanda, así como el entramado de redes sociales en las que se hallan, les permite mantenerse siempre empleadas o con pocos y cortos espacios de desempleo. En términos de integración tal y como ha sido definida arriba no, por cuanto apenas existen cambios de ocupación entre las mujeres de estas nacionalidades independientemente de haber obtenido la nacionalidad española o de haber reagrupado a parte de su familia a lo largo de sus años de estancia.

En conclusión, los procesos de movilidad socio-laboral no están exentos de diferencias entre personas por razones étnicas, de clase y género. La intersección de estos tres factores se convierte en un poderoso aparato limitador en las expectativas de vida de los y las inmigrantes procedentes de países en desarrollo. Las cifras y características de la contratación, el empleo autónomo y la economía sumergida nos revelan comportamientos todavía diferentes entre sexos y orígenes étnicos. Ello va a seguir siendo así a menos que algún tipo de medidas de discriminación positiva sean tomadas, lo cual es bastante improbable por su coste e impopularidad. O que los y las emigrantes movilicen todos los recursos disponibles (nuevas oportunidades del mercado, nueva condición jurídica, habilidades previas y posteriormente adquiridas, afán de superación, cooperación y competencia, etc.) con el fin de mejorar su posición. Y ello, por supuesto, se tendrá que hacer nuevamente a costa de quien venga más tarde.

Nos centraremos aquí en el estudio de caso de la situación de las peruanas por ser éste un colectivo de fuerte inmigración en los noventa que está presentando interesantes cambios en su forma de asentarse y acceder al mercado de trabajo español. Paralelamente veremos las diferencias con respecto a otras nacionalidades. 


\section{LOS NUEVOS PUESTOS DE TRABAJO}

En la investigación realizada con peruanas en Barcelona (Escrivá, 1999), se comprobaba que al menos las tres cuartas partes de las entrevistadas se empleaba en el sector laboral del servicio doméstico, a pesar de no haber ejercido esos puestos nunca anteriormente y considerarlos inferiores a su posición social y experiencias profesionales. Aquello entonces fue explicado en términos de oportunidades laborales predeterminadas y constricciones a sus propias carreras profesionales y personales, en pos del bienestar familiar y la movilidad social ascendente obtenida con la emigración. El malestar manifestado por estas mujeres en cuanto a sus condiciones de vida y trabajo - ligado a sus puestos de trabajo - podía aventurar el germen de futuros cambios en sus trayectorias. Pero las condiciones para ello no parecían darse y las perspectivas aparecían inciertas.

De modo general, sería falso hablar de inexistencia de movilidad laboral entre las inmigrantes que se emplean en el servicio doméstico en España. De hecho, un estudio del Colectivo IOÉ $(2001)^{3}$ — que nos servirá para demostrar con números

Tabla 1.

Movilidad entre subsectores en el servicio doméstico.

\begin{tabular}{lcccccc}
\hline & España & Marruecos & Ecuador & Filipinas & R. Dominicana & Perú \\
\hline No han cambiado & & & & & & \\
Siempre interno & 3,9 & 27,2 & 55,5 & 50,3 & 44,0 & 32,5 \\
Siempre fijo & 26,8 & 20,6 & 13,5 & 12,9 & 9,6 & 16,2 \\
Siempre por horas & 41,7 & 15,4 & 5,2 & 6,1 & 3,6 & 12,0 \\
Subtotal & 72,4 & 63,2 & 74,2 & 69,3 & 57,2 & 60,7 \\
Han cambiado & & & & & & \\
Interno a externo & 5,7 & 21,3 & 14,2 & 15,3 & 24,7 & 12,0 \\
Interno-fijo-horas & 2,1 & 8,1 & 3,2 & 6,7 & 7,8 & 9,9 \\
Fijo a horas & 8,3 & 5,1 & 2,6 & 1,8 & 3,6 & 6,8 \\
Interno-externo-interno & 0,8 & 0,0 & 0,6 & 3,7 & 3,0 & 4,2 \\
Otras trayectorias & 10,7 & 2,2 & 5,2 & 3,1 & 3,6 & 6,3 \\
Subtotal & 27,6 & 36,8 & 25,8 & 30,7 & 42,8 & 39,3 \\
\hline
\end{tabular}

Fuente: Encuesta IOÉ a trabajadores de servicio doméstico (Colectivo IOÉ, 2001)

\footnotetext{
${ }^{3}$ El libro está compuesto de diversas partes, referentes a los subsectores de actividad laboral más frecuentes entre las mujeres de origen inmigrante extracomunitario en España. Una primera parte, la más extensa, está dedicada a las características de las trabajadoras del servicio doméstico, a las condiciones y relaciones laborales en ese sector y a los perfiles de movilidad intra e intersectorial.
} 
nuestro argumento - demuestra que la movilidad entre puestos dentro del sector y entre regímenes, del interno al externo y por horas es considerable (tabla 1). De las mujeres por ellos entrevistadas procedentes de seis nacionalidades -incluyendo la española-, las dominicanas y peruanas resultaron ser las que más habían cambiado de subsector con un porcentaje alrededor del $40 \%$. Además del cambio de subsector, motivado generalmente por la necesidad de mayor independencia, los motivos para cambiar de hogar empleador dentro del régimen interno, según recoge la citada encuesta, son mayormente la opción a un mejor empleo (con un $34 \%$ de los cambios), aumentar el salario (13\%), evitar el exceso de trabajo (10\%), eludir malos tratos $(5 \%)$ o buscar un empleador que aceptara darles de alta en la Seguridad Social $(5 \%)$.

Pero no sólo se dan cambios dentro del régimen especial de trabajadores del hogar, sino que, además, las cifras sobre altas y bajas en los diferentes regímenes de la Seguridad Social demuestran que son bastantes más las personas que abandonan este régimen laboral, sobre todo a favor del régimen general, que las que se incorporan, en una proporción de 1 a 6 aproximadamente. Siguiendo los resultados de la encuesta aplicada por el Colectivo IOÉ, que recoge los movimientos entre los principales segmentos ocupacionales de las trabajadoras del Tercer Mundo (ellos nombran: servicio doméstico, limpiezas, hostelería, oficinas y cuenta propia), obtenemos una imagen clara de lo que está sucediendo - aunque, lamentablemente para nuestro propósito, sin especificar nacionalidades. A pesar de que la mayor parte de mujeres inmigrantes trabaja en el sector de servicio doméstico y éste es el que mayor número de nuevas entradas recibe, también es el que presenta mayor movilidad hacia otros segmentos ocupacionales (gráfico 1).

Por la observación llevada a cabo por la autora en los últimos años en el territorio español ${ }^{4}$, hay constancia de que las peruanas llegadas a España entre finales de los años ochenta, y los años noventa han empezado a desempeñarse en número creciente en otros puestos de trabajo que tienen la característica de desarrollarse fuera del ámbito doméstico de los empleadores. Y cabe remarcar esto porque, a diferencia de lo que era la tónica general en los primeros años de estancia, es decir, el trabajo doméstico como única alternativa laboral para las inmigrantes, con el paso de los años empiezan a abrirse nuevas posibilidades de empleo en ámbitos como el comercio y otros servicios (sanitarios, limpieza, mensajería, restauración, etc.) como empleadas por cuenta ajena o por cuenta propia.

\footnotetext{
Las otras partes están dedicadas más escuetamente a los otros subsectores laborales considerados, como son, limpiezas, hosteleríad, oficinas, cuenta propia y, tratado de forma especial, el trabajo sexual. A partir de los datos de fuentes estadísticas oficiales y las respuestas dadas a los cuestionarios aplicados a 1,806 mujeres de diferentes nacionalidades, incluida la española, se pueden ver los patrones de movilidad.

${ }^{4} \mathrm{~A}$ partir del año 2001 se reemprende el seguimiento de las trayectorias socio-laborales de las peruanas que habian sido entrevistadas en anteriores etapas y, además, se va completando la serie de entrevistas con otras nuevas realizadas en Madrid y Sevilla.
} 
Gráfico 1.

Entradas y salidas en los distintos segmentos ocupacionales de las trabajadoras del Tercer Mundo.

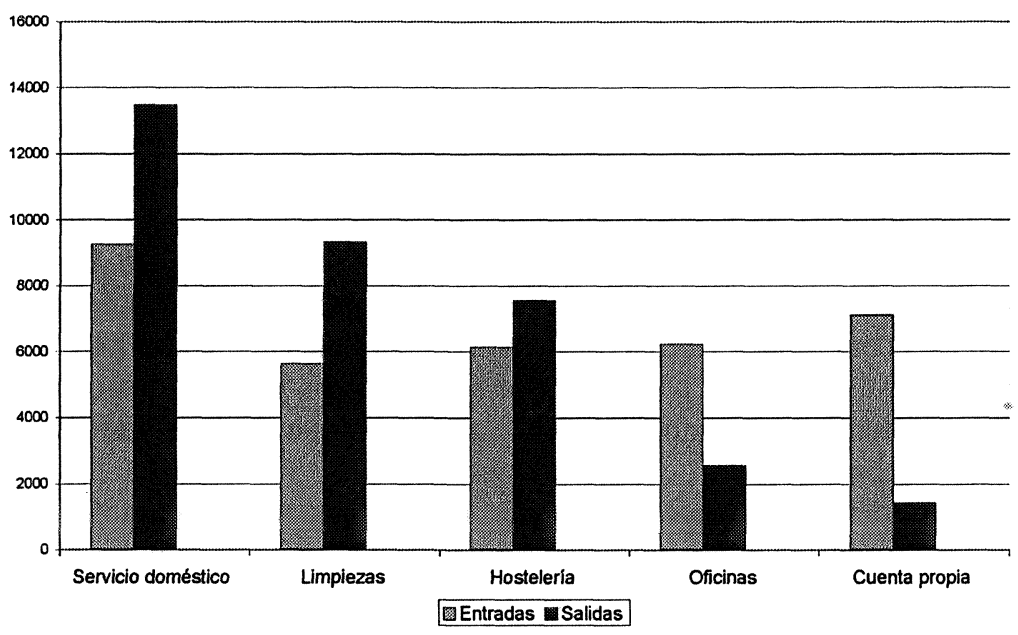

Fuente: Gráfico propio sobre Colectivo IOÉ (2001)

De los datos que recoge el estudio del Colectivo IOÉ sabemos que a fines de 1999, según cifras de altas en la Seguridad Social ${ }^{5}$, eran ya más de 500 mujeres peruanas ocupadas en limpiezas, habiendo la mayor parte de ellas comenzado a trabajar en España en el servicio doméstico. De igual manera, otras más de 500 en esas mismas fechas costaban como ocupadas en hostelería. Muchas menos aparecían ocupadas en oficinas y por cuenta propia. En esta última destacaban las actividades de comercio y hostelería, y en tercer lugar, las actividades de servicios, inmobiliarias y sociales.

Una de las características que reúne a muchos de estos nuevos trabajos es que reproducen la idea de "servir" que encierra el trabajo en el servicio doméstico. Las labores de limpieza, cocina, o puesta de mesa, son labores que también se realizan dentro del hogar, aunque ahora el contexto difiere y la relación laboral no está tan personalizada (con los beneficios y perjuicios que esto puede entrañar para las mujeres inmigradas). Incluimos aquí el trabajo de cuidado de enfermos y ancianos en hospitales y residencias que también reproduce la idea de estas mujeres como cuidadoras. Como reza el artículo de Tamagno (2001) en su estudio sobre

\footnotetext{
${ }^{5}$ Estas cifras deben ser superiores si contabilizamos las mujeres en situación legal irregular y las que han obtenido la nacionalidad española y ya no aparecen, por tanto, en las estadísticas como extranjeras.
} 
RIS

REVISTA INTERNACIONAL DE SOCIOLOCIA

No 36, Septiembre-Diciembre, 2003

ANCELES ESCRIVÁ CHORDȦ

las peruanas en Italia "Debes ganarte su cariño", circula la imagen de que son más dulces y cuidadosas con las personas mayores que las autóctonas, imagen a la que ellas mismas suelen recurrir y explotar en la búsqueda de empleo.

Otra característica presente en muchos de los nuevos puestos es su relación con la economía étnica, es decir: con los negocios en los que la mayoría o totalidad de empleados son extranjeros; con aquellos pertenecientes a personas del mismo lugar de origen (familiares o no); y con los dirigidos a una clientela básicamente de inmigrantes. Entre estos se encuentran los restaurantes de comida internacional, las agencias de viajes y remesas, las de colocación y alquiler de pisos, locutorios, peluquerías, tiendas de productos del país de origen, etc. Cabría citar, además, aunque de forma muy minoritaria, el ascenso de abogadas, tramitadoras, psicólogas, economistas y otras profesionales peruanas dedicadas a los servicios a la comunidad residente en España, y a los contactos y relaciones comerciales, políticas, culturales, de ambos países, quienes operan de forma autónoma o a través de empresas, ONGs, e instituciones oficiales.

La presencia de peruanas en empresas españolas o multinacionales privadas, o en el sector público como empleadas cualificadas, es todavía muy minoritaria. Las razones de su baja incursión deben buscarse, por un lado, en la dificultad para convalidar los títulos obtenidos en el país de origen y colegiarse en aquellas profesiones en donde es necesario para ejercer (también señalado en Oso, 2002). A los títulos cabe sumar la necesidad de reciclar los conocimientos anteriormente adquiridos, adaptándolos a la nueva realidad a través de la formación dentro y fuera del puesto de trabajo. Las oposiciones, paso obligatorio para acceder a la función pública, exigen una larga y costosa preparación que no está al alcance de la mayoría. En vistas a la empresa privada, a menudo falta controlar el manejo de los nuevos códigos sociales y lingüísticos, indispensables para una correcta presentación en el proceso selectivo. Por otro lado, determinados rasgos étnicos, como el aspecto físico, o los estereotipos asociados a ciertas nacionalidades, intervienen negativamente en la elección de candidatas procedentes de los llamados países pobres.

Es necesario señalar algunos aspectos más de la movilidad ocupacional de las peruanas en España. Primero, hemos demostrado que ésta existe - y de modo creciente-, pero que todavía se limita a unas pocas ocupaciones que reproducen muchas de las características de los empleos en el servicio doméstico, que sigue siendo la puerta de entrada. Aparte del tipo de tareas a desempeñar, las similitudes entre los empleos actuales y los anteriores se presentan en la alta irregularidad, inestabilidad y bajo prestigio que tienen los que ahora ocupan: camareras, repartidoras de publicidad, limpiadoras, etc. Segundo, el cambio de sector suele producirse, bien abandonando completamente el servicio doméstico, bien compaginándolo de alguna forma con la nueva dedicación. Aún habiéndolo dejado en un principio, no son infrecuentes los casos de quienes tienen que regresar a trabajar como domésticas después de un periodo fuera poco exitoso (tabla 2). Tercero, el 
abandono de los trabajos como domésticas se produce: después que el puesto se extingue (por muerte del anciano, mudanza de la familia, etc.); reemplazando a la peruana por otra mujer, generalmente de otra nacionalidad extracomunitaria que lleva menos tiempo en España; o sustituyendo a la peruana por otra amiga o familiar de su mismo país que acaba de llegar y está dispuesta al "encierro". De este último modo, algunos puestos de trabajo - los mejores- quedan permanentemente fijados a una nacionalidad, y hasta a una misma familia, que va sustituyendo concatenadamente a la persona que lo ocupa ${ }^{6}$. Mientras que los puestos peores van cambiando continuamente de empleada dentro de una misma nacionalidad o entre nacionalidades?

El efecto que tiene lugar en las relaciones étnicas, de género y las dinámicas familiares tras la movilidad ocupacional debe ser mejor estudiado. Sin embargo, se constata, por ejemplo, una etnización dinámica del mercado laboral al ser reemplazadas sucesivamente las mujeres inmigradas de una nacionalidad con presencia más antigua por aquellas llegadas más recientemente que provienen en su mayoría de otros países: Ecuador, Colombia, o de sustratos sociales más bajos. Esto sucede tanto porque la población autóctona otorga un trato étnicamente diferenciado a las distintas nacionalidades y grupos, como porque los propios individuos inmigrados parten de condiciones sociales diferentes, marcadas por su identificación étnica en origen (no suele vivir ni es percibida de la misma manera una mujer peruana o ecuatoriana con rasgos indígenas poco marcados que la que sí los tiene). Se reproduce la situación étnicamente estratificada que se vive en los países y regiones de origen a la que vienen a sumarse ahora nuevas discriminaciones sobre las antiguas.

El conflicto de género entre hombres y mujeres por la asignación y valoración del trabajo doméstico no se resuelve obviamente mediante su sustitución por la mano de obra inmigrante, simplemente se externaliza. Y para las propias inmigrantes que habían sido señoras o hijas de clase media y profesionales se produce un empeoramiento en su estatus con el empleo doméstico que el trabajo extra-doméstico en las condiciones citadas no mejora sustancialmente pero sí suaviza. De forma generalizada, hemos visto en anteriores estudios (Escrivá, 1999) que el abandono del régimen de interinidad en el servicio doméstico venía dado o se seguía casi inmediatamente por la reagrupación o la formación familiar. De este modo, las que hubieran podido tener hijos y/o esposo les harían venir;

\footnotetext{
${ }^{6}$ Este fenómeno ha ido observándose muy bien entre la inmigración filipina que suele ser muy endogámica y viene produciéndose en buena manera entre la inmigración peruana.

${ }^{7}$ Este mismo proceso puede observarse en el mercado de la vivienda. La dificultad para conseguir pisos de alquiler en buen estado y a precio moderado hace que exista una gran rotación entre inquilinos. Quienes llevan más tiempo y alcanzan mejores condiciones salariales dejan o subarriendan su anterior piso a inmigrantes recién llegados, y así sucesivamente.
} 


\section{RIS}

REVISTA INTERNACIONAL DE SOCIOLOGIA

Tabla 2.

Movilidad entre ramas laborales de las trabajadoras del Tercer Mundo.

\begin{tabular}{lrrrrr}
\hline & $\begin{array}{c}\text { Servicio } \\
\text { doméstico }\end{array}$ & Limpiezas & Hostelería & Oficinas & $\begin{array}{c}\text { Cuenta } \\
\text { Propia }\end{array}$ \\
\hline Trabajadoras actuales & 72.015 & & & & \\
Siempre en la misma rama & 81,8 & & & & \\
Con ocupación anterior & 18,2 & & & & \\
Ocupaciones anteriores: & & & & & \\
Servicio doméstico & - & 68,2 & 34,7 & 28,1 & 18,0 \\
Limpiezas & 9,0 & - & 8,9 & 9,9 & 6,2 \\
Hostelería & 2,1 & 18,5 & - & 16,9 & 26,0 \\
Comercio & 8,1 & 6,2 & 4,2 & 12,5 & 19,4 \\
Oficinas & 1,4 & 3,8 & 1,1 & - & 9,9 \\
Industria textil & 1,7 & 0,9 & 1,6 & 1,2 & 2,4 \\
Agricultura & 0,9 & 0,9 & 0,0 & 0,0 & 1,4 \\
Otros sectores & 2,0 & 7,7 & 2,6 & 19,5 & 17,4 \\
\hline
\end{tabular}

Fuente: Encuesta a trabajadoras extranjeras, Colectivo IOÉ (2001).

otras, llamarían a la emigración a otros familiares; y habría quien pensaría en casarse y formar su familia tras la sustancial mejora económica personal, a la manera como lo han ido haciendo los hombres. En caso de matrimonio no ha sido infrecuente que las peruanas vieran a los varones de origen español -incluso de otras nacionalidades - como buenos candidatos 8 . Para estas últimas el empleo extradoméstico podría verse, bien innecesario como vía para la movilidad social, bien deseable y posible si se obtiene el suficiente apoyo de la parte masculina. Pero lamentablemente muchos hombres han visto en las mujeres extranjeras del Tercer Mundo y de Europa del Este el prototipo de mujer dócil y dedicada al hogar que cada vez les cuesta más encontrar entre sus propias paisanas de generaciones jóvenes.

\footnotetext{
${ }^{8}$ El matrimonio especialmente con españoles es para Oso (2002) una de las principales estrategias que las mujeres inmigrantes utiliza para alcanzar su propia movilidad social, a costa, a menudo, según la autora, de la reducción de las remesas y otros tipos de intercambios con los familiares que quedan en el país de origen; por tanto, en detrimento de la movilidad social de la familia de origen.
} 


\section{DETERMINANTES DE LA MOVILIDAD LABORAL}

No todas las peruanas cuyas trayectorias hemos seguido en el lapso de los últimos diez años han dejado ya el trabajo doméstico remunerado. Algunas ni siquiera han considerado una opción laboral mejor, debido a determinadas condiciones ventajosas que este tipo de empleos les reporta. Entre estas ventajas tenemos: pocos gastos personales en comida y vivienda; abundancia de empleos donde elegir; establecimiento de relaciones personales de amistad y confianza con los empleadores, que les permite, por ejemplo, en determinadas situaciones ausentarse del trabajo y tomar varios meses de vacaciones para ir al Perú, siendo reemplazada por alguna otra persona conocida; incluso su compatibilización con el trabajo de cuidado de sus propios dependientes en el hogar del empleador/a.

Como se explicaba en el artículo referido en la introducción, la frustración inicial al tener que emplearse como domésticas en contra de las propias expectativas solía atenuarse con el tiempo de residencia en España. Hablamos de que muchas mujeres llegaban a conformarse con su situación laboral, ya que a menudo no era tan precaria, contractual y salarialmente, comparada con lo precaria que podía ser la situación fuera del sector. Además, la mayor precariedad de la situación laboral en Perú de la cual las mujeres no eran ausentes, debido a sus visitas y contactos, reforzaba su aceptación y optimismo ante el destino laboral hallado. Con todo, un nutrido grupo, aquéllas más jóvenes, con menos cargas familiares, o con otras expectativas laborales, siguen deseando el desempeño fuera del sector $y$, de manera creciente, han empezado ya a dedicarse a otras ocupaciones que les permiten un mayor contacto con el resto de la sociedad.

Varios son los factores que están posibilitado el acceso a otros ámbitos de empleo. Aquí hablaremos de cinco principales. Más allá de la importancia de cada uno de ellos, hemos de pensar que la movilidad estará propiciada por la conjunción de unos y otros elementos, y que es esa conjunción de fuerzas y no un factor aislado la que explica las razones de la apertura hacia otros segmentos.

Un factor fundamental es el legal. Y en este sentido es donde las peruanas, como el resto de nacionales iberoamericanos - así como filipinos y guineo-ecuatorianos o sefarditas-, disfrutan de ventajas comparativas respecto a extranjeras de otras nacionalidades. El trato preferencial en la concesión y renovación de permisos de residencia y trabajo, en la entrada al país que para algunas nacionalidades sigue sin estar sujeta a la obtención de un visado y en el acceso a la nacionalidad española, se basa en el reconocimiento de un pasado común y un legado histórico y cultural importante para España. Con todo, la legislación sobre extranjería es común para todos los nacionales de países no comunitarios, en la que el sistema de contingentes o cupos es el medio oficial de entrada a la inmigración laboral.

Si bien es cierto que desde que se implantó este sistema de cupos o cuotas en España los permisos iniciales de trabajo para las mujeres peruanas se han restringido al sector del servicio doméstico, también lo es que esto ha facilitado su 
RIS

REVISTA INTERnaCiONal de SOCIOLOGia

No 36, Septiembre-Diciembre, 2003

ANGELES ESCRIVÁ CHORDÁ

rápida integración legal — por ejemplo, más rápida y fácil que la de los hombres peruanos, y que la de extranjero/as de otras nacionalidades para quienes no ha habido la posibilidad de regularizarse o formalizar un contrato desde origen. Todo ello sin olvidar que el régimen general como vía para la contratación inicial, con sus vaivenes, ha estado abierto para los nacionales de Perú sin estarlo para muchos otros.

Para todos ha sido ventajoso además que, a partir de la segunda renovación, el permiso de trabajo deje de restringir la actividad y la localización geográfica, con lo cual se abre legalmente la puerta a nuevas posibilidades de trabajo; datos basados en nuestras propias observaciones de campo demuestran que, a pesar de esta facilidad legal y administrativa, las inmigrantes han seguido manteniéndose mayormente en el mismo ámbito geográfico y laboral en años sucesivos.

Sin embargo, sí se observa que, a medida que se establecen los peruanos en España desde mediados de la década de los noventa, se ha ido produciendo un importante proceso de reagrupación familiar en sentido extenso (hijos, esposos, padres, también hermanos, primos, tíos, cuñados), aprovechando los canales de la reagrupación y los cupos, que ha permitido la entrada regular de la gran parte de las nuevas inmigraciones. Con ello, de nuevo surgen diferencias respecto a nacionales de otros países con mayor número de entradas clandestinas o de situaciones irregulares.

Por último, cabe destacar la ventaja del convenio de doble nacionalidad con una gran parte de los países iberoamericanos y el relativo rápido acceso a la nacionalidad española para quien la solicite (tras sólo dos años de residencia legal y continuada, o sólo un año en caso de matrimonio con español/a). La opción a la nacionalización - que parece estar siendo masivamente tomada por los y las nacionales de Perú, según datos del Ministerio de Interior y nuestras propias observaciones abre las puertas a la colocación en la función pública, pero, además, está llevando en algunos casos a movimientos migratorios intracomunitarios (en Europa) en busca de mayores y mejores ofertas de empleo, permitiéndonos hablar de procesos de movilidad ocupacional en la escala profesional y geográfica9.

Todo lo anterior comporta que los y las peruanas de origen sean uno de los colectivos de reciente implantación en España con mejor situación legal comparativamente respecto a la que hallamos entre otros extranjeros del Tercer Mundo, incluidas algunas nacionalidades latinoamericanas.

Junto a los aspectos de tipo legal, existen otros que completan la gama de factores que determinan la movilidad de las peruanas en el mercado laboral español. Aspectos como las afinidades lingüística, religiosa, cultural y racial, se convierten

\footnotetext{
${ }^{9}$ Este fenómeno ha sido constatado recientemente al conocer que varias personas tienen la intención de o conocen a alguien que ya ha ido a trabajar al Reino Unido como domésticas, enfermeras y otro personal sanitario, o empleados en fábricas. Desconocemos hasta el momento el alcance de estos flujos y si también se producen hacia otros países europeos.
} 
en verdaderos motores explicativos de las diferencias que presentan extranjeros de unas u otras nacionalidades en España en cuanto a sus trayectorias laborales. Son, pues, evidentes las ventajas comparativas de quien habla una misma lengua, mantiene costumbres similares o de raíz común, profesa un mismo culto, tiene apellidos conocidos, ascendientes españoles, rasgos físicos más o menos parecidos, y despierta cierta simpatía o atractivo. De hecho, según hemos observado en las diferentes etapas del trabajo de campo, aquéllas procedentes de los grupos más "criollos" de la sociedad de origen, que forman una buena parte de la inmigración peruana existente en España, son quienes generalmente presentan mejor integración social, en términos económicos y culturales. Ello no quita que, como señala Juliano (1994), la imagen denostada del "indiano/a" sea mantenida, hoy sustentada sobre la división del mundo en ejes económicos.

De ahí que los rasgos socio-demográficos de las peruanas (zonas de origen, procedencia rural o urbana, grupo social de origen, edad, formación académica, estado civil, pareja e hijos) más las trayectorias laborales previas a la emigración tengan asimismo una gran relevancia en la determinación de las posibilidades de promoción ocupacional, como han señalado tanto el Colectivo IOÉ (2001), como Anguiano (2002) en sus trabajos.

En el primer trabajo citado se observa que, sobre una encuesta administrada a mujeres de varias nacionalidades empleadas en el servicio doméstico, las familias de las peruanas proceden más de zonas urbanas que de zonas rurales comparativamente a las dominicanas, filipinas o marroquíes, que son en una mayor proporción de origen rural. De este modo, una menor proporción de las familias de las entrevistadas estaba ocupada en la agricultura antes de que la mujer emigrara, respecto a valores bastante más altos entre las mujeres de las anteriormente citadas nacionalidades, incluida la ecuatoriana ${ }^{10}$.

Esto se explicaría, no tanto por la mayor urbanización de Perú respecto a esos otros países, sino por la selectividad que ha tenido lugar en el caso de las migraciones internacionales. En Escrivá (1999) detallábamos cómo se han ido desarrollando importantes cadenas migratorias desde los principales centros urbanos del país hacia el exterior, en las que han participado muy destacadamente antiguos empleados del Estado y de empresas privadas, así como los hijos e hijas de familias de clase media empobrecida por la crisis económica de finales de los ochenta.

\footnotetext{
${ }^{10}$ Para ofrecer una mejor imagen de la conexión rural-urbana de la emigración, sería importante conocer cuántas de las familias de origen de estas mujeres participaron en procesos de emigración campo-ciudad, considerando los diferentes tipos de hábitat intermedios existentes hasta llegar a las grandes ciudades, y cuántas de ellas mismas pasaron por procesos migratorios internos en el país de origen o emigraron a otros países vecinos para emplearse en los distintos sectores.
} 
RIS

REVISTA INTERNACIONAL DE SOCIOLOGIA

No 36, Septiembre-Diciembre, 2003

ANGELES ESCRIVÁ CHORDÁ

Un rasgo sociodemográfico de vital importancia para entender la movilidad ocupacional es el nivel de formación académica de las mujeres inmigradas. El alto nivel educativo presente entre los nacionales de Perú ha sido objeto de mención por todos los estudios realizados a la fecha (Merino, 2002; Tornos, 1997). En la encuesta a trabajadoras del hogar realizada por el Colectivo IOÉ (2001) queda patente que, proporcionalmente, son más las nacionales de este país con niveles de estudios superiores ( $63,2 \%$ de todas las peruanas entrevistadas) que las de algunas otras nacionalidades $(17 \%$ de las dominicanas o el $11 \%$ de las marroquíes, por ejemplo), sin menoscabo de las colombianas o argentinas que no fueron tomadas en la muestra del estudio. Sin haber finalizado los estudios o teniendo sólo los primarios apenas aparece un $5,8 \%$, mientras que, entre dominicanas y marroquies, este porcentaje se eleva al $40 \%$.

Este elevado nivel de formación forma parte del capital humano con el que las mujeres acceden al mercado laboral, propiciando, en un primer momento, la frustración ante las escasas alternativas laborales y, posteriormente, el deseo de realizar tareas más acordes con sus cualificaciones y experiencias.

El problema de la inadecuación de las cualificaciones y experiencias aportadas por las peruanas - que han sido mayoritariamente profesoras, empleadas administrativas, psicólogas, abogadas, asistentes sociales...- con las demandas del mercado es de difícil solución, aunque se evidencia que las inmigrantes tienen mayor iniciativa a la hora de obtener soluciones "intermedias" que muchas otras españolas que se encuentran en igual situación. Algunas la resuelven reciclando sus conocimientos hacia segmentos de esas especialidades en las que puede haber demanda: las abogadas especialistas en asuntos de extranjería, las asistentas que trabajan como mediadoras interculturales o en las ONG, para el desarrollo, etc. Otras optan por la realización de nuevos estudios superiores de postgrado, donde de nuevo, al finalizar, las distancias entre las demandas y las ofertas pueden no haberse acortado. Un tercer sector explora la posibilidad de realizarse en nuevos campos, que requieran quizás menos estudios académicos, pero que en definitiva exigen cierta capacitación y profesionalización. Entre ellos tenemos las que incursionan en los oficios de panadería, y otros de la alimentación, la producción fabril y artesana, y demás.

No hemos de olvidar a aquéllas que tienen conocimientos y experiencia en el sector sanitario. Una vez regularizadas, mejor aún, nacionalizadas, y con sus estudios convalidados y complementados con conocimientos específicos de geriatría, nutrición, estética, pasan a emplearse en lo posible en empresas públicas y privadas del ramo de la salud, dejando los puestos de cuidadoras de personas mayores y enfermas en los hogares a otras mujeres sin los necesarios conocimientos sanitarios. Esto repercute indudablemente en la calidad de estos servicios.

Hacer mención a otro rasgo sociodemográfico que nos parece decisivo y que tiene que ver en buena medida con los procesos descritos de reagrupación y formación familiar. Las peruanas presentan el porcentaje más elevado de soltería de 
los encontrados entre las entrevistadas del servicio doméstico por el Colectivo IOÉ (2001), en torno al 50\%. Otra vez este estudio nos ayuda a comparar estos datos con los de número de hijos y edad. La proporción de solteras contrasta con la de madres, ya que una proporción menor, el $44 \%$, declara no tener ningún hijo, lo cual nos lleva a pensar que estamos ante un número de madres solteras (declaradas). Mis propias observaciones durante el trabajo de campo realizado durante varios años me hacen creer que este número es mayor que el que aquí aparece, ya que los casos de madres solteras fueron entonces muy numerosos.

Asimismo, llama la atención el número de peruanas mayores de 45 años empleadas en el sector $(24,6 \%)$ - sólo superado un poco por las españolas, y doblado por las mujeres filipinas, cuya inmigración es de mayor antigüedad en España y ha vivido menor renovación. Pero frente a éstas o frente a las españolas empleadas en el servicio doméstico, hay proporcionalmente más peruanas entre los 25 y los 44 años. Mucha mayor juventud presentan las nacionales de República Dominicana, Marruecos y, sobre todo, Ecuador.

Con estos datos podemos intuir que, primero, las posibilidades de inserción y movilidad ocupacional, en definitiva, de integración laboral de una mujer casada que de una mujer soltera y con ningún hijo no son las mismas. El hecho de no tener que compaginar el cuidado de los miembros familiares dependientes una vez reagrupados, cual es la tónica general entre las que los tienen con el trabajo remunerado, repercute en una mayor dedicación e inversión en este último. Esto podría estar pasándole a un porcentaje de peruanas.

Por otro lado, debido a la existencia entre ellas de importantes grupos de trabajadoras en todos los rangos etarios, a excepción del de 18 a 24 años, nos hace pensar que - contrario a la filipina, que es una inmigración globalmente envejecida - las actuales domésticas peruanas han ido llegado escalonadamente en el tiempo después de haber tenido experiencias laborales - y posiblemente también formación- previa en otros ámbitos. Ello podría justificar el empuje que demuestran hacia la consecución de otros empleos. Sin embargo, las oportunidades laborales y el deseo de promoción y cambio desciende muy significativamente en el grupo de las mayores. A excepción de actividades dentro del propio hogar (costura, cocina, artesanía) o el autoempleo que demanda cierta inversión, estas mujeres están abocadas a continuar en el régimen de trabajadoras del hogar hasta que se jubilen.

Todo lo anterior no sería suficiente para explicar la movilidad laboral si no incluimos en el análisis otros aspectos coyunturales, como son: a) la dinámica del mercado laboral, y b) las estrategias de colocación utilizadas por las inmigrantes.

La situación del mercado laboral es fundamental para entender la mayor o menor apertura a la integración de trabajadoras inmigrantes en nuevos puestos. Porque aunque las condiciones legales ya estaban dadas en buena parte de la década de los noventa, no es sino hasta bien entrada su segunda mitad cuando el relativo "despegue" económico habido posibilita el acceso a otros trabajos extra- 
RIS

REVISTA INTERNACIONAL DE SOCIOLOCIA

No 36, Septiembre-Diciembre, 2003

ANGELES ESCRIVÁ CHORDÁ

domésticos. El crecimiento del sector servicios en las grandes capitales españolas - que es en el que mayoritariamente se insertan las peruanas, en ámbitos como la restauración-, acontece ante un crecimiento del turismo, los intercambios comerciales y las ventas en general que acompañan a cualquier proceso de expansión económica. No hablaríamos, pues, de una simple sustitución de trabajadores autóctonos por inmigrantes en estos puestos sino de la nueva creación que permite, por un lado, la movilidad de los autóctonos hacia ámbitos y condiciones más deseadas, y la entrada de inmigrantes, especialmente de ciertas nacionalidades con las cuales existen condiciones ventajosas, como hemos visto.

Mas el análisis económico de la migración queda sesgado si no introducimos el componente dinámico de creación de empleo propio por los inmigrantes. Como vimos al hablar de las características de los nuevos puestos, una importante puerta de salida o entrada (en el caso de quienes no necesitan pasar por el empleo doméstico) al mercado laboral extra-doméstico son los negocios étnicos, cuya magnitud y dinamismo no debe ser menospreciado. En el caso peruano, han florecido los restaurantes llevados en buena parte por mujeres, las agencias de colocación y alquiler de inmuebles, las tiendas de alimentación - importación y elaboración -, los locutorios telefónicos, y otros. Son negocios por y para la comunidad inmigrante pero en el que también intervienen factores de la economía local. A veces pueden estar incursionando de manera pionera en nichos económicos todavía no explotados por los capitales nacionales. Y así como en otros países ciertas nacionalidades se han distinguido por el dinamismo de su economía étnica, como en el caso de los coreanos en Estados Unidos (Bonacich et Light, 1991), también puede esperarse que ocurra en España con aquellas nacionalidades de origen mejor dotadas en capital social.

En el relativo éxito de las peruanas en el proceso de movilidad laboral argumentaré aquí lo que considero es otro aspecto fundamental que junto a las cuestiones legales, culturales, sociodemográficas y de experiencia previa, y a la situación del mercado laboral, determina el relativamente rápido cambio de actividad de muchas de estas mujeres. Tiene que ver, por una parte, con las estrategias migratorias de los peruanos en España en general, que pasaron en pocos años de basarse en proyectos femeninos cuasi individuales a corto plazo, a proyectos a largo plazo de reagrupación completa de las familias extensas. La existencia de una gran red familiar en España - compuesta mayormente por miembros activos económicamente y por algunos familiares cuidadores, las mujeres mayores- posibilita que los distintos miembros puedan pasar por periodos de más o menos actividad económica, dediquen más tiempo a la búsqueda de empleo, puedan permitirse elegir puestos con mayor riesgo de éxito, y menor apremio por ganar dinero a corto plazo, ofreciendo, por tanto, alternativas a los trabajos establecidos por los nichos étnicos como el servicio doméstico.

Más aún, mi hipótesis es que el cambio en las estrategias familiares ha permitido la diversificación de los sexos con lo que la presencia de miembros 
masculinos ha podido dar empuje a las carreras migratorias femeninas. Ello explicaría, por ejemplo, las diferencias significativas de movilidad ocupacional entre mujeres (filipinas, dominicanas) con también elevados niveles de instrucción en algunos segmentos y largo tiempo de estadía. El elemento distintivo entre estos tres colectivos parece hallarse en la composición por sexos, más equilibrada en el caso peruano. En mi observación del caso de las mujeres peruanas, he podido constatar como algunas comenzaron a trabajar como camareras o mensajeras, a raíz de que un familiar masculino llegado después de ellas se insertó en alguna de estas ocupaciones. Ello podría haber llevado a una especie de efecto demostración, por el cual las mujeres entendieran que otro tipo de actividad era posible y que, además, tenían quien les ayudara a dar el paso.

\section{CONCLUSIONES}

El hecho de que las mujeres hayan sido en muchos casos pioneras e independientes en el proceso migratorio desde los países en desarrollo hacia los más desarrollados ha sido comúnmente valorado como signo de empoderamiento femenino. Más allá de la huída de la pobreza o la violencia (del hogar o del Estado), su marcha, y las consecuencias para estas mujeres en el plano económico y social han sido traducidas en clave de superación y mejora general de su estatus. Ello justificaría la menor tendencia al retorno voluntario que presentan respecto a sus compatriotas masculinos (Hondagneu-Sotelo, 1994), además de otros aspectos desestimulantes como las dificultades que puedan hallar para abrir sus propios negocios en el lugar de origen, o el olvido o ignorancia con el que son tratadas sus necesidades y potencialidades desde las políticas de sus países respecto a las comunidades emigradas.

Sin embargo, hay varias cuestiones que quedan pendientes. Una de ellas tiene que ver conque estas mujeres realizan mayoritariamente el trabajo doméstico de mantenimiento del hogar y del cuidado de niños, enfermos y ancianos, en sustitución de otras a quien tradicionalmente se les asignaba este tipo de tareas. Éste es un rasgo frecuente en las sociedades actuales, tanto desarrolladas, como en desarrollo, aunque también lo ha sido para determinadas clases sociales en el pasado. Las propias peruanas que viven en España conocen de primera mano que, como en Perú, la inserción de la mujer en el trabajo remunerado y la llamada clase media pasa por el trasvase de las labores del hogar a mujeres de estratos sociales inferiores. Por tanto, estas emigrantes que se sienten pertenecientes a clases sociales medias y que poseen, en muchos casos, mejor preparación y experiencia en el mercado laboral remunerado que muchas españolas, ven frustrados sus intentos de movilidad social al tener que desarrollar trabajos domésticos.

Las posibilidades de cambiar de puestos hacia segmentos laborales más cualificados, mejor considerados, o para los que ellas se sienten más preparadas o moti- 
vadas para trabajar son todavía escasas y han sido poco exploradas. Las peruanas, no obstante, presentan una de las más altas tasas de movilidad ocupacional entre las inmigradas del Tercer Mundo en España. Aquí hemos argumentado cuáles podrían ser los factores determinantes de estas mejores posiciones. Con todo, la realidad nos dice que los nuevos puestos escalados siguen siendo en buena parte inestables, poco cualificados, mal retribuidos y/o poco o medianamente valorados socialmente.

La segunda cuestión pendiente en la mejora del estatus femenino tiene que ver con la reagrupación familiar y la mayor presencia de hombres en el colectivo. En la primera mitad de la década de los noventa, se constata que la reagrupación incluye mayormente miembros femeninos de la familia, amigas o vecinas. De este modo, las nuevas incorporaciones no varían sustancialmente los roles asignados a las mujeres. Se forman entre ellas verdaderas cadenas solidarias que facilitan la emigración de quienes se lo solicita y en España se informan y se pasan empleos dentro del sector doméstico. Hacia finales de los noventa, sin embargo, desde que los contingentes se estabilizan y las posibilidades de entrada clandestina a través de países como Alemania se ven dificultadas, los hombres comienzan a sumarse en igual o mayor número a la entrada de mujeres. Pero en su caso, no son los lazos con amigos o compatriotas los que les abren el campo, sino sus mujeres (parejas, hermanas, madres) quienes les informan, les consiguen un contrato, les reagrupan o les invitan.

La llegada de más varones tiene, a mi ver, varias consecuencias inmediatas. La carga de trabajo doméstico en los hogares de las inmigradas aumenta, puesto que ellos no tienen la mínima intención de compartirlas. Ello deriva en que las mujeres puedan dedicar menos tiempo al trabajo remunerado, a su formación, $\mathrm{y}$ a las necesarias relaciones sociales que la búsqueda de un mejor empleo necesita. Segundo, el hecho de que muchos hayan tenido que iniciarse laboralmente en España en el servicio doméstico - como cuidadores de personas ancianas, chóferes, mayordomos o jardineros,- - les iguala en principio en sus condiciones de vida. Pero en realidad, suelen abandonar este tipo de empleos en cuanto pueden y ya se encargan ellos de dejar claro cuán diferentes son sus labores respecto a las femeninas. Por tanto, no encontramos tampoco una redefinición de roles en estos casos. Tercero, si hemos de señalar un aspecto positivo en la llegada de más hombres es la diversificación de los empleos. Aquí se ha argumentado como factor determinante de la movilidad ocupacional femenina, el hecho de que los peruanos hayan conseguido puestos como camareros, repartidores y panaderos, ha tenido un efecto "demostración" en las mujeres. Algunas han imitado a los varones abandonando sus puestos domésticos. En ello, convienen, que han obtenido numerosas ventajas comparativas.

He centrado mi análisis en el caso de las mujeres peruanas adultas que llegaron a lo largo de la década de los noventa a España y que residen habitualmente en las grandes áreas de Madrid y Barcelona principalmente. Para comprender el impacto 
de la inmigración laboral femenina y masculina del Tercer Mundo en el mercado español debiéramos obtener información sobre las distintas nacionalidades de origen. Mas no ha sido ese nuestro propósito, sino de centrar la atención sobre una de las nacionalidades que más contribuyó al crecimiento del sector doméstico, sobre todo, en su vertiente de cuidado de personas mayores, durante la pasada década. Viendo cómo ha evolucionado descubrimos, además, nuevos itinerarios y perfiles. Sabemos más sobre cómo la emigración altera los estados ya cambiantes de los emigrantes. Y sabemos más sobre cómo ésta cuestiona el orden dominante: no porque necesariamente se enfrente a él, sino porque lo pone en mayor evidencia. Nos referimos, es claro, entre otras muy importantes realidades, a la de la asignación -ineludible e incuestionada - del trabajo doméstico a las mujeres.

Deseo proponer una agenda de investigación para los próximos años. Ella debería incorporar el seguimiento de los cambios y desplazamientos por nacionalidades en el servicio doméstico. De este modo pueda comprobarse que, como intuyo, en adelante se produzca tal proceso de sustitución étnica que los peores puestos (por ser internos, mal pagados y duros) recaigan cada vez más en las inmigradas de los más bajos niveles sociales - desde el país de origen - y de ciertos orígenes étnicos (las más indígenas, las más negras). La investigación debería incorporar adicionalmente un interés por conocer los avances que se puedan estar gestando desde las administraciones públicas españolas por equiparar la situación del régimen de empleadas del hogar a los otros regímenes, cuál podría estar siendo el papel de la inmigración en este sentido, y qué efecto podría tener en la mayor desiderabilidad de estos empleos.

Dado que la población envejece rápidamente, estamos ante un importante reto económico y social al que los diversos actores deben encontrar respuestas. Una podría hallarse en el reparto de responsabilidades entre los sexos y el Estado. Cuestión que debe ser detalladamente estudiada a la luz de las propuestas que surjan tanto en España como en el ámbito europeo. Parece preocupar y mucho la cuestión del reemplazamiento generacional y el pago de las pensiones del creciente número de jubilados. Mucho menos se está proponiendo sobre quién se encargará y de qué manera se dispondrán los cuidados necesarios para la atención de los ancianos y otros miembros dependientes si las mujeres jóvenes en España no desean realizar estas tareas en exclusiva. Tampoco las que llegan parecen estar dispuestas a hacerlo en el largo plazo. Y, además, dejan sin resolver estos mismos problemas en su lugar de origen, donde quedan familiares a su cargo. Será interesante ver qué estrategias de reagrupación y sustitución utilizan para compaginar ambos trabajos.

Por último, en la línea que aquí se discute, proponemos continuar con el seguimiento de las carreras ocupacionales de las peruanas con mayores o menores niveles educativos. Cómo otros factores, como el elemento asociativo y la mayor o menor participación ciudadana, pueden influir en ese proceso. Podemos intuir que el avance hacia puestos extra-domésticos no acabe en lo que aquí hemos señalado. 
RIS

REVISTA INTERNACIONAL DE SOCIOLOCIA

No 36, Septiembre-Diciembre, 2003

ANGELES ESCRIVÁ CHORDÁ

El dinamismo y la capacidad de generación que inmigrantes de otras latitudes demuestran puede ser equiparado. Además, queda por ver los caminos que sigan las subsiguientes generaciones. En ese caso, no habrá que obviar el importante número de descendientes de parejas mixtas, con españoles o con otros extranjeros, en que habrán de combinarse diferentes puntos de partida. Cabe recalcar que, si el caso peruano nos parecía especialmente interesante de ser presentado, es también porque a pesar de su relativamente reciente incorporación ha mostrado grandes cambios, entre los que se halla su masiva opción por la nacionalización. Lo cual deberá considerarse, asimismo, en las proyecciones futuras de ésta y otras nacionalidades iberoamericanas.

\section{REFERENCIAS BIBLIOGRÁFICAS}

ANGUIANO, M.E. (2002), Emigración reciente de latinoamericanos a España: trayectorias laborales y movilidad ocupacional, Ponencia presentada al III Congreso sobre Inmigración en España, Granada, 6-9 Noviembre.

BAUBÖCK, R. (1994), The integration of immigrants, Council of Europe, Estrasburgo.

ESCRIVÁ, A. (1999), Mujeres peruanas del servicio doméstico en Barcelona: trayectorias sociolaborales, Tesis doctoral, Universidad Autónoma de Barcelona.

BONACICH, E. et I. LIGHT (1991), Immigrant Entrepreneurs: Koreans in Los Angeles, 1965-1982, Columbia y Princeton, University Presses of California.

BORDERÍAS, C. et al. (comps.) (1994), Las mujeres y el trabajo. Rupturas conceptuales, Barcelona, Icaria.

CARRASCO, C. (1991), El trabajo doméstico. Un análisis económico, Madrid, Ministerio de Trabajo y Seguridad Social, Colección tesis doctorales, $n^{\circ} 31$.

CASTLES, S. (1998), "New migrations, ethnicity and nationalism in Southeast and East Asia", online paper, Transnational communities programme, Oxford University.

COLECTIVO IOÉ (2001), Mujer, inmigración y trabajo, Madrid, Instituto de Migraciones y Servicios Sociales.

DELEGACIÓN DEL GOBIERNO PARA LA EXTRANJERÍA Y LA INMIGRACIÓN (2002), Anuario estadístico de extranjería 2001, Madrid, Ministerio del Interior.

ESCRIVÁ, A. (2000), “¿Empleadas de por vida? Peruanas en el servicio doméstico de Barcelona”, Papers, $\mathrm{n}^{\circ}$ 60, pp. 327-342.

HONDAGNEU-SOTELO, P. (1994), Gendered Transitions: Mexican Experiences of Immigration, Berkeley, University of California Press. 
JULIANO, D. (1994), "La construcción de la diferencia: los latinoamericanos", Papers, n 43, p. 23-32.

LIEM, P. (2000), Steadily Forward. Status attainment of Surinamese in the Netherlands, Amsterdam, Tesis doctoral, Thela Thesis.

MERINO, A. (2002), Historia de los inmigrantes peruanos en España. Dinámica de exclusión e inclusión en una Europa globalizada, Madrid, CSIC.

MTAS (1997), El servicio del hogar familiar, 1997, Madrid, Ministerio de Trabajo y Asuntos Sociales.

OSO, L. (2002), "Stratégies de mobilité sociale des domestiques immigrées en Espagne", Revue Tires Monde, v. XLIII, $\mathrm{n}^{\circ} 170$.

POAL, G. (1993), Entrar, quedarse, avanzar. Aspectos psicosociales de la relación mujer-mundo laboral, Madrid, Siglo XXI de España editores.

SOWELL, T. (1997), Migrations and Cultures: a World View, Nueva York, Basic books.

TAMANGO, C. (2001), "Debes ganarte su cariño”, en N. Sorensen (ed.), N. Work and migration, Londres, Routledge.

TORNOS et al. (1997), Los peruanos que vienen. Quiénes son y cómo entienden tipicamente la inmigración los inmigrantes peruanos, Madrid, UPCO.

UNITED NATIONS (1997), International migration and development, Nueva York, Naciones Unidas.

WERNER, H. (1993), Integration ausländischer Arbeitnehmer in den Arbeitsmarkt-Deutschland, Frankreich, Niederlande, Schweden - working paper: migration and population, Ginebra, OIT. 